\title{
Conceptual design of a portable electrolyzed water cleaning rig using TRIZ method
}

\author{
${ }^{1}$ Jalil, N.A., ${ }^{1}$ Khalid, N.I., ${ }^{1}$ Sulaiman, N.S., ${ }^{2}$ Sobri, S., ${ }^{1}$ Taip, F.S. and ${ }^{1,3, *}$ Ab Aziz, N. \\ ${ }^{1}$ Department of Process and Food Engineering, Faculty of Engineering, Universiti Putra Malaysia, 43400 \\ Serdang, Selangor, Malaysia. \\ ${ }^{2}$ Department of Chemical and Environmental Engineering, Faculty of Engineering, Universiti Putra \\ Malaysia, 43400 Serdang, Selangor Darul Ehsan, Malaysia \\ ${ }^{3}$ Halal Products Research Institute, University Putra Malaysia, 43300 UPM Serdang, Selangor, Malaysia.
}

\author{
Article history: \\ Received: 19 May 2020 \\ Received in revised form: 7 \\ August 2020 \\ Accepted: 15 December 2020 \\ Available Online: 18 April \\ 2021
}

Keywords:

Electrolyzed Water,

Green Cleaner,

Water Jet,

Biodegradable,

Sustainable Technology

DOI:

https://doi.org/10.26656/fr.2017.5(S1).048

\begin{abstract}
The limited budget allocation and storage chemicals space are the main reasons food SMEs manufacturers took cleaning and sanitation for granted. A portable electrolyzed water cleaning rig which can generate sanitation solution and at the same time generated high-speed water will ease the cleaning and sanitation process for SMEs. In this study, the theory of inventive problem solving (TRIZ method) is applied in the development of a portable electrolyzed water cleaning rig. A new conceptual design for the rig, which is robust and affordable is proposed. The rig could improve cleaning efficiency significantly in SME food industry in Malaysia, which is a major cause of a low number of SME with GMP certification. However, the final conceptual design has to undergo several modifications for assembly and manufacturing purposes, which will be performed in further study. The idea of generation for the portable electrolyzed water cleaning rig design was illustrated based on the TRIZ contradiction matrix. This portable rig will be able to generate both strongly acidic electrolyzed water (AcEW) and strongly alkaline electrolyzed water (AlEW) solution continuously. Both cleaning solutions are green cleaning solutions which can replace the commercial cleaning sanitation solutions. The development of the conceptual design of the portable water cleaning rig will help food SMEs tremendously.
\end{abstract}

\section{Introduction}

Electrolyzed water can be separated into two types of solutions which are alkaline electrolyzed water (AlEW) and acidic electrolyzed water (AcEW) with the presence of the membrane (Huang et al., 2008; Rahman et al., 2016). Both solutions have high potential to be used in the cleaning process of the food industry as the alkaline solution containing sodium hydroxide that is highly effective in grease-cutting cleaner (Hsu, 2005; Hricova et al., 2008). Meanwhile, for an acid solution, it is highly effective in disinfecting as it contains high dissolved oxygen and chlorine in hypochlorous acid (Hricova et al., 2008). Electrolyzed water can be used as a green cleaner to clean and disinfect foodborne pathogens as it is environmentally friendly. This is because electrolyzed water will return to normal water after interacting with the organic matter (Colangelo et al., 2015). Electrolyzed water is being used in various fields of application such as in the medical, dental, food- processing, agriculture, and dairy industries for cleaning purpose (Kim et al., 2000; Al-Haq et al., 2005; Hung et al., 2008).

Currently, there has an increment of demand in utilizing electrolyzed water as a green cleaner either in the large industries, kitchen, home or medical since it has an effective effect on disinfecting the microbial and grease cleaner. Various kinds of innovations are available in the patent database for electrolyzed water cleaning units such as a generator, hand-held portable cleaning unit and portable rig cleaning unit. However, most of the innovation for electrolyzed cleaning unit is more focusing in producing neutral electrolyzed water (NEW) rather than producing both acidic electrolyzed water (AcEW) and alkaline electrolyzed water (AlEW) (Kaestner et al., 1974; Nakamura et al., 2000; Nakamura et al., 2005; Field et al., 2007; Arai et al., 2018). This is because the $\mathrm{pH}$ solution for NEW that is the range within 6 to 8 has sterilizing effect without causing rough skin or 
the corrosion to the equipment (Kaestner et al., 1974; Nakamura et al., 2005; Arai et al., 2017). Furthermore, high $\mathrm{pH}$ solution has a longer shelf life compared to the low $\mathrm{pH}$ solution in which the chlorine is largely in the form of hypochlorous acid and it has a limited shelf life (Kaestner et al., 1974).

In this paper, a new portable electrolyzed water cleaning rig is developed by using the TRIZ method. The concept of designing a portable cleaning rig is to produce electrolyzed water that is continuously supplied from the electrolytic cell and hot water. However, there have some issues for the strongly acidic electrolyzed water and strongly alkaline electrolyzed water to be produced in continuous type as the electrolysis solution passes through the electrolytic cell in an extremely short period (Arai et al., 1996; Shirota et al., 2001). Thus, it will be difficult to produce the desired $\mathrm{pH}$ for both strongly electrolyzed water. For this issue, a new concurrent engineering technique which is TRIZ was applied as a problem-solving method in the development of a conceptual design for the portable electrolyzed water cleaning rig. Therefore, the objective of this study was to design a new portable electrolyzed water cleaning rig which can produce both strongly acidic electrolyzed water (AcEW) and strongly alkaline electrolyzed water (AlEW) solution continuously.

\section{Materials and methods}

2.1 Design criteria of the portable electrolyzed water cleaning rig

Design criteria for the portable cleaning rig were determined by conducting an industrial survey among the small-medium food industry. The findings of this survey have shown that they need cleaning apparatus that has those features:

- Portable as they need to move the cleaning apparatus from another unit operation to another unit operation during the cleaning process.

- Cleaning medium temperature can be adjusted that suit the type of soil to be removed.

- On-site generation of cleaning and disinfectant medium so that no storage is needed for the chemicals and chemical cost can be omitted.

- Suitable size for moving around the production aisle.

- No wastewater treatment for cleaning discharge.

- Extensive rinsing after chemical rinse can be reduced.

- Pressure spraying for difficult to clean area.

\subsection{TRIZ method}

TRIZ method was introduced as a comprehensive technique as it provides a logical approach to the development of innovation creativity and inventive problem solving (Savranksy, 2000). The concept of the TRIZ is aiming to find the ideality of the solution by overcoming the contradiction that exists for the design solution. In order to accomplish the requirement of the design solution, TRIZ method assists the process of analyzing the design idea by getting the improving feature and eliminating the worsening feature simultaneously (Mansor et al., 2014). According to the Altshuller, most of the product has similar problems of the design and the problems are repeated over the industries and it also found that the solutions are based on how the others have resolved it and adapt it to be used to solve these problems.

The TRIZ contradiction matrix is used in this method as the problem solver to determine the appropriate solution for resolving all the design intent problems. All the possible problem in designing a portable electrolyzed water cleaning rig should be identified first in achieving the design goal. As the problem has been identified, it will come out with the possible improvements and worsening parameters that are matched correctly from the list of the 39 engineering parameters. Those of the improving and worsening parameters are required in order to construct the TRIZ contradiction matrix in which to determine the best solution from the 40 Inventive Principle for solving the problem. After the solution principle have been proposed on the contradiction matrix, the most relevant principle will be selected as a guideline to develop a new portable electrolyzed water cleaning rig design.

\section{Results and discussion}

In this part, the description of how the TRIZ method solves the problems in the development of the new design of a portable electrolyzed water cleaning rig is given. The TRIZ contradiction matrix is being used during the analysis of the problem design, to improve the parameter which is negatively affected by another parameter. A contradiction was identified first by analyzing a problem that could occur from the design of a portable electrolyzed water cleaning rig. By identifying the contradiction, it will help in getting the idea and selecting the 40 inventive principles to overcome such contradictions in the matrix.

By referring to Table 1 and Table 2, the contradiction matrix of a portable electrolyzed water rig and also the design strategy was based on the identified 
Table 1. Contradiction matrix for portable electrolyzed water cleaning rig

\begin{tabular}{llll}
\hline \multirow{2}{*}{ No } & \multicolumn{1}{c}{ Improving feature } & \multicolumn{1}{c}{ Worsening feature } & TRIZ solution principles \\
\cline { 2 - 4 } 1. & $\begin{array}{l}\text { 313. Stability of the object's } \\
\text { composition }\end{array}$ & 39 Engineering parameters & 40 Inventive principles \\
\hline 2. & $\# 14$. Strength & $\#$ 30. Object affected harmful factors & Principle 40: Composite material \\
\hline 3. & $\# 21$. Power & \#26. Quantity of substance & $\begin{array}{l}\text { Principle 15: Dynamization } \\
\text { Principle 13: The other way around }\end{array}$ \\
\hline 4. & $\# 34$. Ease of repair & \# 30. Object affected harmful factors & Principle 9: Preliminary anti-action \\
\hline
\end{tabular}

Table 2. Design strategy based on identified TRIZ solution principles

\begin{tabular}{lll}
\hline TRIZ solution principle & \multicolumn{1}{c}{ Solution description } & \multicolumn{1}{c}{ Design strategy description } \\
\hline \#3. Local quality & $\begin{array}{l}\text { (i) Change an object's structure from uniform } \\
\text { to non-uniform, change an external } \\
\text { environment (or external influence) from } \\
\text { uniform to non-uniform }\end{array}$ & $\begin{array}{l}\text { (i) Used a method of circulating electrolysis } \\
\text { system in an electrolytic cell }\end{array}$ \\
\hline \#9. Preliminary anti-action & $\begin{array}{l}\text { (i) If it will be necessary to do an action with } \\
\text { both harmful and useful effects, this action } \\
\text { should be replaced with anti-actions to control } \\
\text { harmful effects }\end{array}$ & $\begin{array}{l}\text { (i) Adding corrosive inhibitor to the electrolyte } \\
\text { in order to reduce the corrosive }\end{array}$ \\
\hline \#13. The other way around & $\begin{array}{l}\text { (i) Make movable parts (or the external } \\
\text { environment) fixed, and fixed parts movable }\end{array}$ & $\begin{array}{l}\text { (i) Adjusting the space between the electrode } \\
\text { by using electrode mover }\end{array}$ \\
\hline \#15. Dynamization & $\begin{array}{l}\text { (i) Allow (or design) the characteristics of an } \\
\text { object, external environment, or process to } \\
\text { change to be optimal or to find an optimal }\end{array}$ & $\begin{array}{l}\text { (i) Use optimal spacing between the electrode } \\
\text { within the range of the 1-10 mm }\end{array}$ \\
\hline operating condition & $\begin{array}{l}\text { (i) Change from uniform to composite } \\
\text { (multiple) material }\end{array}$ & $\begin{array}{l}\text { (i) Build the electrolytic cell from material of } \\
\text { polyvinyl chloride to withstand corrosion } \\
\text { resistant }\end{array}$ \\
\hline
\end{tabular}

TRIZ solution principles. Based on the first contradiction, one of the criteria of the design is to generate a constant $\mathrm{pH}$ value of strong alkaline electrolyzed water and strong acidic electrolyzed water at $\mathrm{pH} 12$ and 2.7 respectively, but it would be difficult to produce as the electrolysis solution continuously pass through the electrolytic cell in an extremely short period. Therefore, the parameter that should be improved is the stability of the object's composition (\#13), but the parameter that worsens is the area moving object (\#5). The suggested inventive principle is 3 for the use of local quality (3). One possible solution could be used is a method of circulating electrolysis solution (Deguchi and Osamura, 1997; Shirota et al., 2001). The repeated of the electrolysis solution that circulated in an electrolytic cell will accumulate a cation and an anion, thus can provide a constant $\mathrm{pH}$ value at 2.7 and 12 for strong acidic electrolyzed water and strong alkaline electrolyzed water respectively. The $\mathrm{pH}$ measuring device may be provided in the circulation container of electrolytic cell for detecting the $\mathrm{pH}$ value of both electrolyze water solution.

For the second contradiction, the other criterium of the design is to improve the strength of the electrolytic cell material as it come into contact with the strong acidic electrolyzed water since their $\mathrm{pH}$ value is very low and it can corrode the equipment. Hence, strength (\#14) is a parameter to be improved while the worsen parameter is the object affected harmful factors (\#30). As the contradiction has been identified, the principle 40 is selected for the use of composite material. The possible solution to build the electrolytic cell wall with composite material like polyvinyl chloride which can withstand the corrosive environment of a chlor-alkali, high resistance to chemical, excellent electrical insulation properties, lightweight and readily fabricated and moulded, taking into account the suggestion of the principle 40 (Peters et al., 1977; Nakamura et al., 2000).

In addition, the third contradiction is to use a small amount of voltage to cut the cost of the power supply by adjusting the spacing between the electrodes plate, but if the spacing between the electrode is too small it will reduce the amount of the electrolyzed water production. The distance between the electrode plate should be larger after electrolysis has started in order to decrease the strength of the electric field (Shiramizu et al., 1998). As the electric field strength has been decreased it can prevent the $\mathrm{H}^{+}$ion and $\mathrm{OH}^{-}$ion that is produced at anode and cathode respectively from being attracted the $\mathrm{H}^{+}$ion and $\mathrm{OH}^{-}$ion to the cathode and anode respectively. In short, the $\mathrm{H}^{+}$ion should remain in the anode to increase $\mathrm{H}^{+}$concentration around the anode, while $\mathrm{OH}^{-}$ion remains in the cathode to increase the $\mathrm{OH}^{-}$concentration 
around the cathode. Thus, the parameter of the power (\#21) is selected as an improving component, but the worsening parameter is the quantity of substances (\#26). The inventive principle of dynamization (\#15) and the other way around (\#13) are chosen to overcome this contradiction. The order of the solution principles that are being proposed is related to the highest use frequency in a similar situation in other types of problems. For the principle of dynamization (\#15), there are preferably to use optimal spacing between the electrode within the range of the 1-10 $\mathrm{mm}$ (Nakamura et al., 2000). Meanwhile, for the principle of the other way around (\#15), there are using the electrode mover to adjust the space of the electrodes in which the distance between the electrodes is reduced when the electrolysis is to start and gradually increased after electrolysis has started (Shiramizu et al., 1998).

Next contradiction is to increase the life cycle of the electrode, but the chlorine gas that is easily generated during producing the strongly acidic electrolyzed water will lead to the corrosion material of the electrode. The electrode should have a longer life cycle so that the electrode would not need frequent replacement or maintenance since it will consume much cost. Thus, the parameter that needs to be improved is the ease of repair (\#34) and the worsen parameter is object affected harmful factors (\#30). The preferably of the inventive principle as a solution to the contradiction is preliminary anti-action (\#9). The principle of the preliminary antiaction provides an idea to add the corrosion inhibitor to the electrolyte in order to reduce the corrosive.

Using the design strategy that is adopted from the TRIZ solution principle, it provides the idea in generating and developing the conceptual design of the portable electrolyzed water cleaning rig as shown in
Figure 1.

Referring to Figure 1, a water storage tank will be filled with the tap water at room temperature and then the water is heated by using the heater. The heating process will be conducted up to a certain temperature where the thermocouple is provided for sensing and measuring the temperature of the water. At the same time, the tap water and electrolysis solution will be entering into the electrolytic cell. In the electrolytic cell, there is a three-cell configuration with two membranes where the electrolysis solution will be passed through the centre of the electrolytic cell. The electrolysis solution is continuously and repeated supply to the electrolytic cell through a circulating electrolysis system flow so that a cation and anion will be accumulated to produce the strongly acidic electrolyzed water and strongly alkaline electrolyzed water that are having the constant $\mathrm{pH} 2.7$ and 12 respectively. In order to get the constant $\mathrm{pH}$ value for both electrolyzed water, each of the cathode and anode chamber is provided with the $\mathrm{pH}$ sensor respectively for sensing the $\mathrm{H}^{+}$concentration or $\mathrm{OH}^{-}$ concentration in the solution. Both the cathode and anode chamber are equipped with the valve so that a user can choose either AcEW or AlEW as a cleaning medium for cleaning process. A pump will move the preferable amount of electrolyzed water to the spray gun. Besides, a by-pass valve also is equipped in the design in which to release the accumulated pressure in the system.

\section{Conclusion}

By using the TRIZ contradiction matrix, the problem of the technical part of a portable electrolyzed water cleaning rig can be solved by following the solution of 40 inventive principles. The problem that has been solved help to improve and simplify the function model

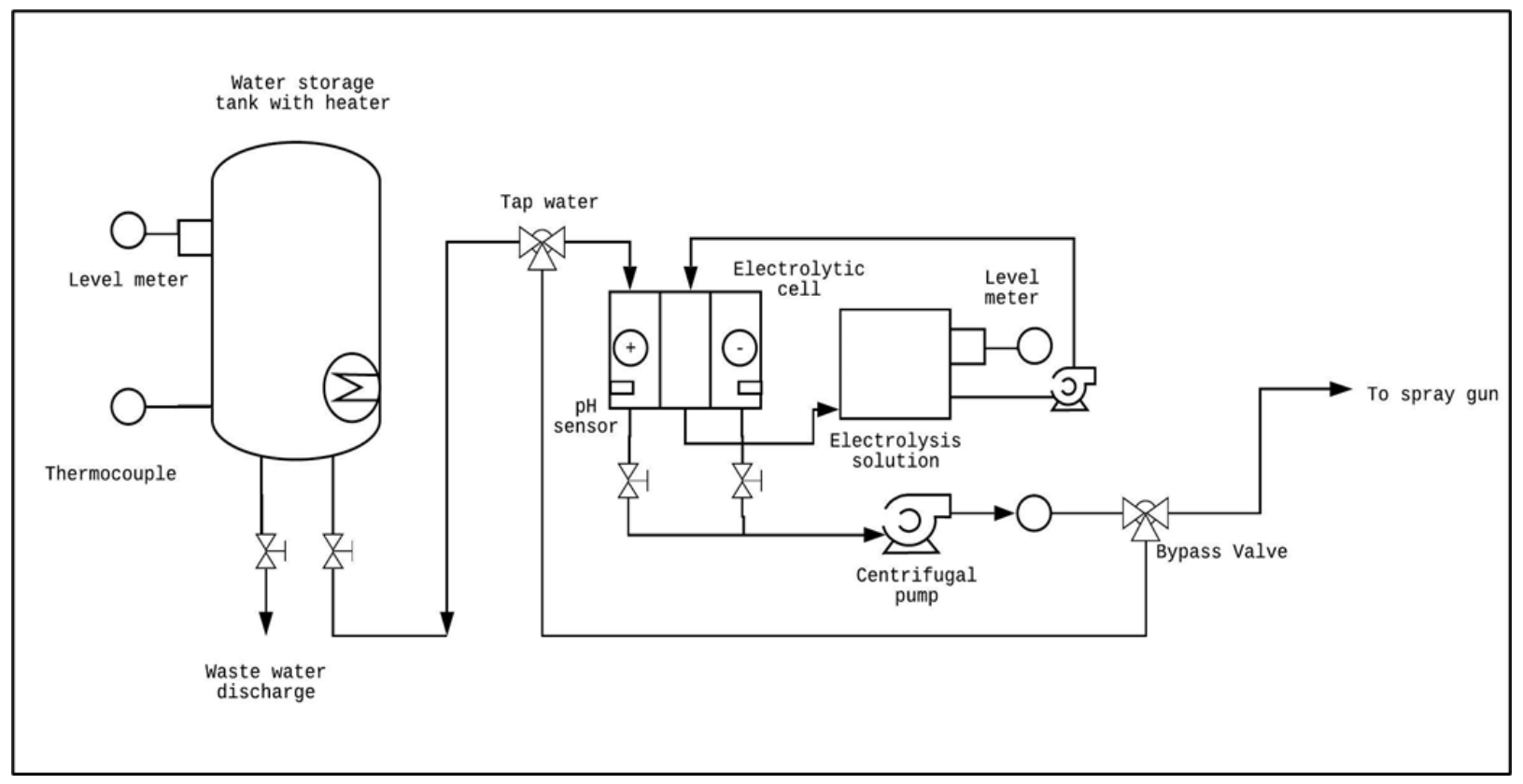

Figure 1. P\&ID diagram for a portable electrolyzed water cleaning rig 
of a cleaning unit that makes it innovative design. The innovative design of a new portable electrolyzed water cleaning rig not only has the same functions with the other existing cleaning unit but also this new design of the cleaning unit can produce the cleaning solutions (AcEW and AIEW) that are environmentally friendly. AcEW can be used to replace the acidic-based detergent and sanitizer. While AlEW can substitute the alkalinebased detergent. Thus, this will help Food SMEs greatly in reducing the cost of purchasing commercial cleaning solutions.

\section{Conflicts of interest}

The authors have declared no conflict of interest.

\section{Acknowledgement}

The authors would like to acknowledge the financial support provided by Ministry of Higher Education (FRGS/2/2013/TK05/UPM/02/14) Fundamental Research Grant Scheme.

\section{References}

Al-Haq, M.I., Sugiyama, J. and Isobe, S. (2005). Applications of Electrolyzed Water in Agriculture and Food Industries. Food Science and Technology Research, 11(2), 135-150. https://doi.org/10.3136/ fstr.11.135

Arai, K., Shoda, I., Kohno, N., Sato, T. and Okamoto, Y. (1996). U.S. Patent No. 5,510,009. Washington, DC: U.S. Patent and Trademark Office.

Arai, N. and Hayashi, N. (2017). U.S. Patent No. 0314179 A1. Washington, DC: U.S. Patent and Trademark Office.

Arai, N. and Hayashi, N. (2018). U.S. Patent No. 0141833 A1. Washington, DC: U.S. Patent and Trademark Office.

Colangelo, M.A., Caruso, M.C., Favati, F., Scarpa, T., Condelli, N. and Galgano, F. (2015). Electrolysed water in the food industry as supporting of environmental sustainability. In Vastola, A. (Ed.). The Sustainability of Agro-food and Natural Resource Systems in the Mediterranean Basin, p. 385-397. Verona, Italy: Springer Link. https:// doi.org/10.1007/978-3-319-16357-4

Deguchi, K. and Osamura, K. (1997). U.S. Patent No. 5,624,544. Washington, DC: U.S. Patent and Trademark Office.

Field, B.F. and Gronlund, P.J. (2007). U.S. Patent No. 0186957 A1. Washington, DC: U.S. Patent and Trademark Office.

Hricova, D., Stephan, R. and Zweifel, C. (2008).
Electrolyzed water and its application in the food industry. Journal of Food Protection, 71(9), 193447. https://doi.org/10.4315/0362-028X-71.9.1934

Hsu, S.Y. (2005). Effects of flow rate, temperature and salt concentration on chemical and physical properties of electrolyzed oxidizing water. Journal of Food Engineering, 66(2), 171-6. https:// doi.org/10.1016/j.jfoodeng.2004.03.003

Huang Y.R., Hung, Y.C., Hsu, S.Y., Huang, Y.W. and Hwang, D.F. (2008). Application of electrolyzed water in the food industry. Food Control, 19(4), 329345. https://doi.org/10.1016/j.foodcont.2007.08.012

Kaestner, E.A. and Spink, J. (1974). U.S. Patent No. 3,819,329. Washington, DC: U.S. Patent and Trademark Office.

Kim, C., Hung, Y.C. and Brackett, R.E. (2000). Efficacy of electrolyzed oxidizing (EO) and chemically modified water on different types of foodborne pathogens. International Journal of Food Microbiology, 61(2), 199-207. https:// doi.org/10.1016/S0168-1605(00)00405-0

Mansor, M.R., Sapuan, S.M., Zainudin, E.S., Nuraini, A.A. and Hambali, A. (2014). Conceptual design of kenaf fiber polymer composite automotive parking brake lever using integrated TRIZ-Morphological Chart-Analytic Hierarchy Process method. Materials and Design, 54, 473-482. https://doi.org/10.1016/ j.matdes.2013.08.064

Nakamura, S., Fukuzuka, K. and Fujii, H. (2000). U.S. Patent No. 6,113,853. Washington, DC: U.S. Patent and Trademark Office.

Nakamura, S., Fukuzuka, K. and Miyashita, M. (2005). U.S. Patent No. 6,926,819 B2. Washington, DC: U.S. Patent and Trademark Office.

Peters, E.J. and Zeman, W.P. (1977). U.S. Patent No. 4,032,424. Washington, DC: U.S. Patent and Trademark Office.

Rahman, S.M.E., Khan, I. and Oh, D.H. (2016). Electrolyzed Water as a Novel Sanitizer in the Food Industry: Current Trends and Future Perspectives. Comprehensive Reviews in Food Science and Food Safety, 15(3), 471-490. https://doi.org/10.1111/15414337.12200

Savranksy, S.D. (2000). Engineering of creativityintroduction to TRIZ methodology of inventive problem solving. Boca Raton, Florida: CRC Press.

Shiramizu, Y., Nakamori, M., Aoki, H., Seo, H. and Hamano, H. (1998). U.S. Patent No. 5,762,779. Washington, DC: U.S. Patent and Trademark Office.

Shirota, K. and Isaka, A. (2001). U.S. Patent No. 6,294,073 B1. Washington, DC: U.S. Patent and Trademark Office. 